\title{
Experimental Study of Tensile Properties of the Steel-plastic Geogrids
}

\author{
Qingbiao Wang ${ }^{1,2,3}$ Rongshan Lü ${ }^{1}$, Yingchun Kong ${ }^{1}$, Lei Xu ${ }^{1}$, Cong Zhang ${ }^{1}$, Fei Xie ${ }^{1}$, Tao Zheng ${ }^{1}$, \\ Zhen Chen ${ }^{1}$, Lingyu Tang ${ }^{1}$ and Hui Wang ${ }^{*}, 1$
}

${ }^{I}$ College of Civil Engineering and Architecture, Shandong University of Science and Technology, Qingdao Shandong 266590, China; ${ }^{2}$ Department of Resource and Civil Engineering, Shandong University of Science and Technology, Taian, Shangdong 271019, China; ${ }^{3}$ Shandong Hualian Mining Co., Ltd., Yiyuan, Shangdong, 256119, China

\begin{abstract}
As a kind of supporting material applied to the supporting structure, steel-plastic geogrid mainly goes through the tensile strength to bear the load from the rock mass. Tensile strength is an important indicator of the steel-plastic geogrid mechanical properties. Tensile strength directly affects the security and stability of the steel geogrid in support of the project. Through the test of indoor geogrid stretching which combines different sizes' geogrids with different elongation rates, tensile strengths of these geogrids were compared. The findings are as follows: (1) The stretching rate has a significant effect on the tensile property of steel-plastic geogrid. When the strain is constant, the higher the stretching rate is, the lower the tensile strength of the geogrid will be. When the stretching rate is constant, the greater the strain plastic geogrid is, the greater the tensile strength will be; (2) The peak degree always decreases with the extension rates' increase; a higher tensile strength material means a smaller reducing amplitude; under the conditions of the same stretch rate, the lower the tensile strength of the geogrid is, the higher the peak strain will be; (3)The influences on different geogrids vary when the tensile rates are different. Steel-plastic geogrid get less influenced by the stretching rate than the plastic geogrid.
\end{abstract}

Keywords: Tensile modulus, tensile property, the steel-plastic geogrid, tensile strength.

\section{INTRODUCTION}

Geogrids, for its advantages of high strength, good durability and convenient installation, has been widely used in the highways, railways, and mine fields. As the reinforcement material applied to the supporting structure, it mainly passes through the tensile strength to bear the load of soil.

In the past, researchers mainly studied the geogrid's tensile properties on the side of geotextile. Moraci [1] studied the method of the pullout resistance of geogrids. Hou $\mathrm{J}$ [2] studied the pullout test of bidirectional geogrid with strengthen node. Cai Chun and Zhang Mengxi [3] studied reinforced reinforcement soil interface's properties of the rib of geogrid by lots of pullout experiments, and discussed factors affecting the ultimate pullout resistance, and deduced the formula of pullout resistance in theory. Shi Youzhi and Ma Shi Dong [4] evaluated the geogrid interfacial friction coefficient between geogrid and sand gravel, coarse sand, residual soil by the experiments of geogrid interface characteristics. Luan Maotian, Xiao Chengzhi [5] took a test on the creep properties of geogrid under different conditions where both loads and temperatures vary according to the needs of this test. Through the indoor test, the following conclusions have been drawn: They learnt about the creep characteristics of geogrids and proposed constitutive model of viscoelastic creep properties of geogrids. Yang ye and Liu Songyu [6] studied the new technology about testing

*Address correspondence to this author at the Department of Resource and Civil Engineering, Shandong University of Science and Technology, Taian, Shangdong 271019, China; Tel: +8618805381111;

E-mail: 1349725165@qq.com geogrids' stress condition, and then they found that the electric induction measurement of displacement of geogrid was accurate and reliable. Wu Jinghai [7] studied the geosynthetic interface properties by pullout test, and found that the drawing coefficient of warp knitting geogrid was higher than plastics geogrids, geosynthetic was the lowest. GaoJie [8] discussed the tensile mechanism of the geotechnical grid and studied the influence of the process conditions on the properties of the geotechnical grid by experiments. Yang Guangqing, Lv Peng [9] studied the plastic geogrid's tensile properties by the tension test.

In recent years, although the new model reinforcement material, the steel-plastic geogrid was widely used in reinforced soil engineering. However, the corresponding experiments and researches carried out, do not meet the demand, and there are many factors in the application which would influence the tensile properties of geogrid. Therefore, it is necessary to study how the tensile rate influences the steel-plastic geogrid in the tension test when the tensile tests are carried out.

\section{THE STEEL-PLASTIC GEOGRID OVERVIEW}

\subsection{Concept and Scope of Application}

Based on plastic geogrid, the steel-plastic geogrid is made up of high strength steel wires processed specially, and PE or PP and other additives. Steel wires are wrapped by PE or PP by special fusing, then these form compound and high strength tensile bands with rough surface, and the following procedure is that longitudinal and transverse bands experience a knitting procedure into a system at certain 
distance. Then, a special welding technology is used to bond the junction points into the steel-plastic geogrid. Changing the diameters of steel wires and quantity improve the tensile strength of geogrid. The steel-plastic geogrid can enhance tensile strength of geogrid, be more good at resisting creep properties, and prolong the service life of the grid, which is suitable for coal mine, highway, railway, airport, well irrigation, civil construction and so on.

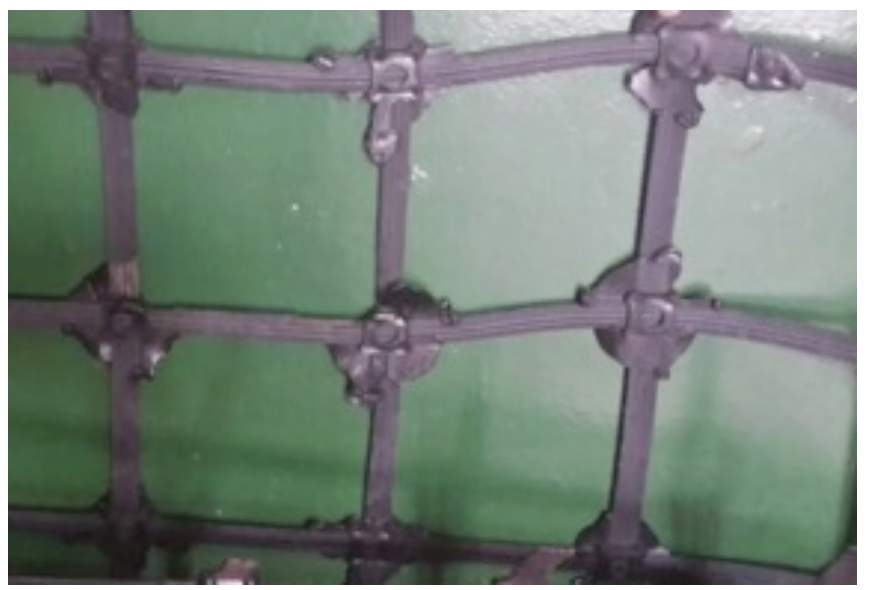

Fig. (1). The steel-plastic geogrid.

\subsection{Composition of Raw Materials}

The steel-plastic geogrid's reinforcement and its application in engineering are directly influenced by materials of the geogrid and the steel wires' strength. Therefore, it is necessary to meet these demands that the materials must have good impact toughness, good creep resistance, and good resistance to environmental stress and aging. And then the geogrid should be kept in a stable state in the using process.

\subsection{Production Process}

(1) Preparation of materials. According to the production of the product specifications, it is mixed with new PE raw materials and recycling of material particles; then measured. Technicians use blenders to mix the ingredients well with adding color, defoamer and other accessories.

(2) Adding materials. Add the PE material to the extruder; Put steel wire in the mold.

(3) Heating and forming. Don't stop to heat PE materials by extruder until the $\mathrm{PE}$ is in a plastic state. Technicians pour PE into molds and make it wrapped into steel, then cool down with cold water.

(4) Geogrid welding. Technicians use ultrasonic wave emitted by high frequency welding parts to weld geogrid.

\section{THE STEEL-PLASTIC GEOGRID TENSILE CHARACTERISTIC INDEX}

The tensile strength is the most important index of the geotechnical geogrids, which is used in the supporting structure of the mine tunnel. The tensile strength is expressed by the tensile force of the unit length, and the unit is $\mathrm{kN} / \mathrm{m}$ or $\mathrm{N} / \mathrm{m}$. In tensile test, the tensile strength of the geotechnical geogrids are affected by factors, such as the width, the shape, the test fixture and the external environment. So the tensile test must be carried out in accordance with the standards.

Elongation is another main index of the geogrid. It is usually expressed as a percentage of the original length of the elongation of the sample. The calculation formula is:

$$
\delta=\Delta L / L
$$

$\Delta L$ is the change quantity of tensile length of geogrid, and, $L$ is the original length. The elongation can be directly obtained through the test or is calculated by the elongation curve. The stress - strain curves of the geogrids are usually nonlinear, and the tensile modulus is generally referred to the modulus of a tensile range. So, methods of determining the tensile modulus are also different.

\section{EXPERIMENT TENSILE PROPERTIES OF STEEL- PLASTIC GEOGRID}

The laboratory experiment is an important means to analyze the stress state of steel-plastic geogrids and engineering properties of the reinforced soil structure .It is very important to effectively analyze the tensile properties of the reinforced soil structure of geotechnical grid. The present approaches of studying on the performance of grid reinforcements are mainly based on a variety of standards or specifications. Various parameters are determined by the tensile experiment at a certain tensile rate determined in the specification.

\subsection{Test Preparation}

In order to study the effect of different tensile rates on the tensile properties of steel-plastic geogrids, we selected three kinds of different specifications of the steel plastic geogrids in the uniform and different strain rates $(50,10,1,0.1$, $0.05 \mathrm{~mm} / \mathrm{min}$ ) tensile experiment research. Test equipment for the DR028J universal material testing machine, as shown in Fig. (2). The main technical specifications of the 3 models are shown in Table 1; A for two-way plastic geotechnical geogrids, B, C for two-way steel-plastic geogrids. The experiment was carried out at $(20+2){ }^{\circ} \mathrm{C}$ constant temperature and $(60+5) \%$ relative humidity conditions, which used the fixture to clamp the steel-plastic geogrid by the universal testing machine, as shown in Fig. (3). The whole experiment process is controlled by universal testing machine.

\subsection{The Results of Tensile Test}

Under the condition of room temperature, the tensile test was done on three different grids. Different results were obtained, and the analysis was carried out.

\subsubsection{The Results of Tensile Test on Type A}

As can be seen from Fig. (4), type A of geotechnical geogrid in the process of tensile experiment, with the increase of the load, the deformation and displacement of the geogrid is also increasing, and the tensile curve shows a 
Table 1. Main index of the geogrids in test.

\begin{tabular}{|c|c|c|c|}
\hline \multirow{2}{*}{ Type } & \multicolumn{3}{|c|}{ Type and Specification } \\
\hline & A & $\mathbf{0}$ & C \\
\cline { 2 - 4 } & $\geqq 105.0$ & $\mathbf{0 . 7 m m * 1 2}$ & $\mathbf{0 . 7 m m * 1 8}$ \\
\hline \hline Vertical (horizontal) to tensile strength $(\mathrm{kN} / \mathrm{m})$ & $\geqq 25.2$ & $\geqq 30.4$ & $\geqq 136.0$ \\
\hline The tensile strength of the $2 \%$ longitudinal strain(kN/m) & $\geqq 49.8$ & $\geqq 61.2$ & $\geqq 38.5$ \\
\hline The tensile strength of the $5 \%$ longitudinal strain(kN/m) & $\leqq 15.5$ & $\leqq 15.5$ & $\leqq 15.5$ \\
\hline Peak strain/\% & & & \\
\hline
\end{tabular}

rising trend. When the pulling force achieves $5.9 \mathrm{kN}$, tensile curve decreases rapidly, the load decreases rapidly to zero, which demonstrates that the geogrid has pulled off, the tensile strength reduced to 0 . As can be seen from Fig. (4), the displacement of A type of geotechnical geogrid is proportional to the tensile strength before reaching the tensile strength limit of the geogrid.

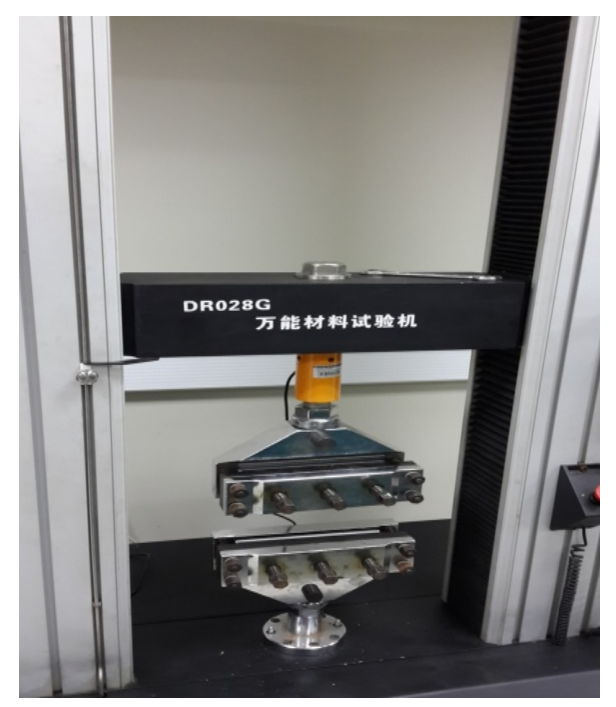

Fig. (2). Universal material testing machine.

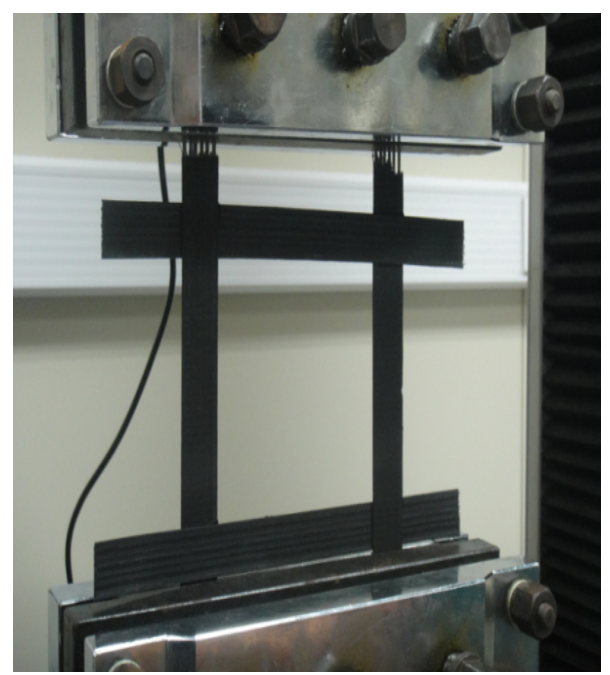

Fig. (3). Universal material testing tensile geogrids.

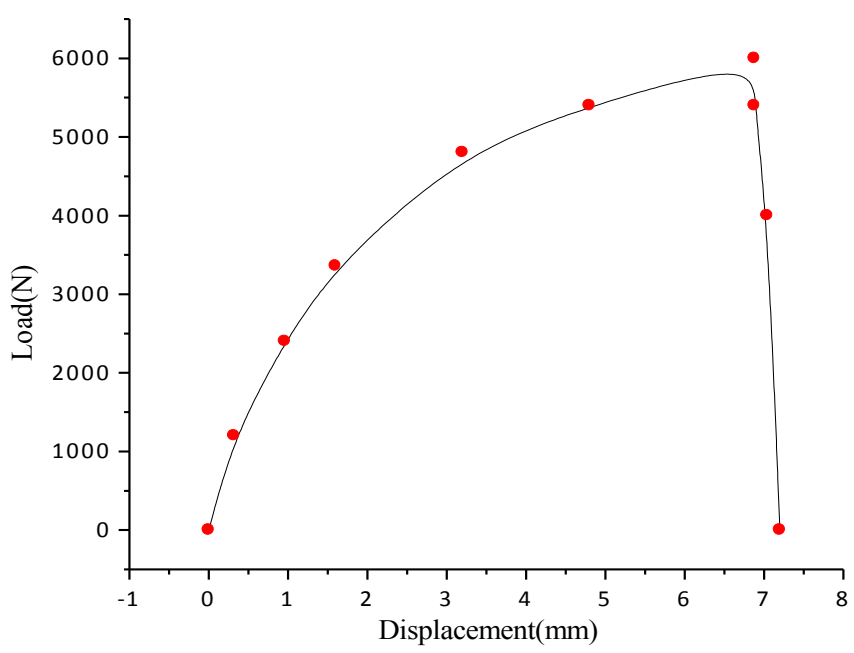

Fig. (4). Tensile test result of A geogrids at a steady speed.

As can be seen from the Table 2: Stretching rate decreased from $50 \mathrm{~mm} / \mathrm{min}$ to $0.05 \mathrm{~mm} / \mathrm{min}$. Under the $2 \%$ strain condition, the tensile strength and tensile modulus of the type A of geotechnical geogrid decreased by $20.02 \%$. Under the $5 \%$ strain condition, the tensile strength and tensile modulus of type A were decreased by $19.03 \%$. In contrast, the peak strain of the geotechnical geogrid increased by $23.36 \%$.

\subsubsection{The Results of Tensile Test on Type B}

As can be seen from the Fig. (5), the drawing process of B type grating can be divided into 3 stages: low load and large deformation stage, high load and small deformation stage, and fracture stage. In the beginning of the loading process, it was a low load and large deformation stage: the tensile load was very small, the tensile deformation displacement was larger, and finally reached the $19.2 \mathrm{~mm}$. Then it entered the second stage-the high load and small deformation stage, in this stage, as the load increases, the deformation displacement of geogrid was increasing gradually. As can be seen from the Fig. (5), the increase of the tensile curve was large, however in the same load difference, the change of displacement of the second stage was smaller than that of the first stage, that is only $6 \mathrm{~mm}$. When the load reached $12.29 \mathrm{kN}$, it entered the third stage that is the fracture stage. In the fracture stage, steel wires in the geogrid belt were broken, the tensile curve of steel wires was suddenly dropped, and the tensile strength was reduced to 0 . From the analysis, it can be known that the tensile strength of the B type geogrid was influenced by steel wires, 
Table 2. Tensile test result of A geogrid at a different speed.

\begin{tabular}{|c|c|c|c|c|c|c|}
\hline \multirow{2}{*}{ Type } & \multirow{2}{*}{$\begin{array}{c}\text { Tensile Rate } \\
(\mathbf{m m} / \mathbf{m i n})\end{array}$} & \multicolumn{2}{|c|}{ 2\% Strain } & \multicolumn{3}{|c|}{ 5\% Strain } \\
\cline { 3 - 7 } & & Tensile Strength (kN/m) & Tensile Module (kN/m) & Tensile Strength (kN/m) & Tensile Modulus (kN/m) & Strain/\% \\
\hline \hline A & 50 & 30.56 & 986.96 & 60.43 & 790.4 & 10.76 \\
\hline A & 10 & 27.98 & 963.9 & 54.77 & 773.0 & 751.8 \\
\hline A & 1 & 26.54 & 942.5 & 52.09 & 694.2 & 11.32 \\
\hline A & 0.1 & 25.73 & 869.0 & 50.10 & 663.7 \\
\hline A & 0.05 & 24.44 & 822.3 & 48.93 & 12.54 \\
\hline
\end{tabular}

Table 3. Tensile test result of $B$ geogrid at a different speed.

\begin{tabular}{|c|c|c|c|c|c|c|}
\hline \multirow{2}{*}{ Type } & \multirow{2}{*}{$\begin{array}{c}\text { Tensile Rate } \\
(\mathbf{m m} / \mathbf{m i n})\end{array}$} & Tensile Strength $(\mathbf{k N} / \mathbf{m})$ & Tensile Module (kN/m) & Tensile Strength (kN/m) & Tensile Modulus (kN/m) & Strain/\% \\
\hline \hline B & 50 & 48.67 & 1770.7 & 93.45 & 1279.1 \\
\hline B & 10 & 44.31 & 1701.4 & 85.56 & 1202.3 \\
\hline B & 1 & 41.69 & 1639.0 & 79.65 & 10.07 \\
\hline B & 0.1 & 40.95 & 1546.5 & 79.01 & 1146.7 \\
\hline B & 0.05 & 39.87 & 1499.6 & 77.87 & 1103.2 \\
\hline
\end{tabular}

and the tensile strength of the grid reached the minimum when the steel wire broke.

As can be seen from the Table 3: Stretching rate decreased from $50 \mathrm{~mm} / \mathrm{min}$ to $0.05 \mathrm{~mm} / \mathrm{min}$. Under the $2 \%$ strain condition, the tensile strength and tensile modulus of the B type of the steel-plastic geogrid decreased by $18.08 \%$. Under the 5\% strain condition, the tensile strength and tensile modulus of type B geogrids were decreased by $16.67 \%$. In contrast, the peak strain of the geotechnical geogrid increased by $20.52 \%$

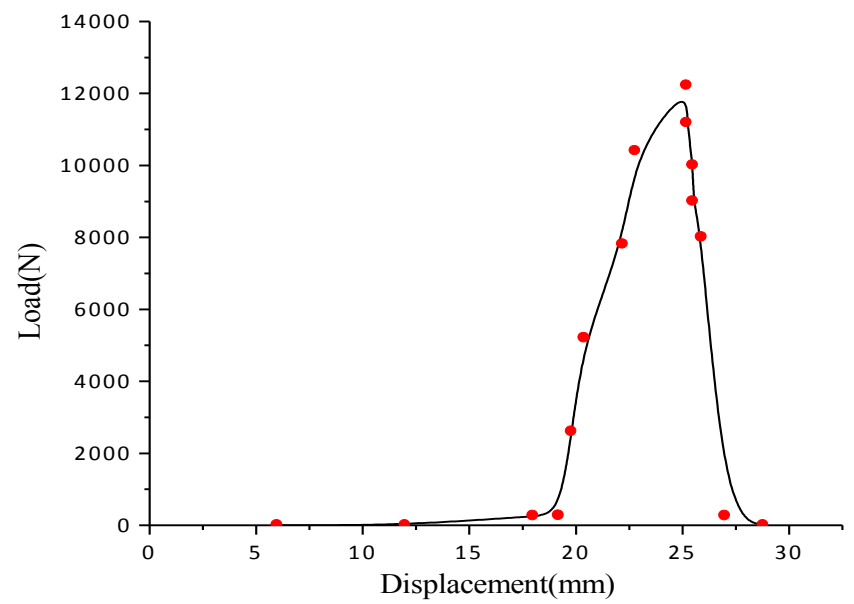

Fig. (5). Tensile test result of B geogrid at a steady speed.

\subsubsection{The Results of Tensile Test on Type C}

As can be seen from Fig. (6), the drawing process of the type $\mathrm{C}$ geogrid was similar to the drawing process of the type B geogrid, which could be divided into two stages: tensile stage and silking stage. Before reaching the ultimate tensile strength, the tensile displacement of the geogrid became larger with the increase of the tensile load. When the tension reached $17.28 \mathrm{KN}$, steel wires and polyethylene coating layer were peeled off. At the same time, the steelplastic geogrid laddered in the fixture. However, the tension of steel wires had not been fully played. So, there is still a certain strength of steel-plastic geogrid. After being pulled up to a certain intensity, the curve dropped rapidly, and the strength decreased gradually.

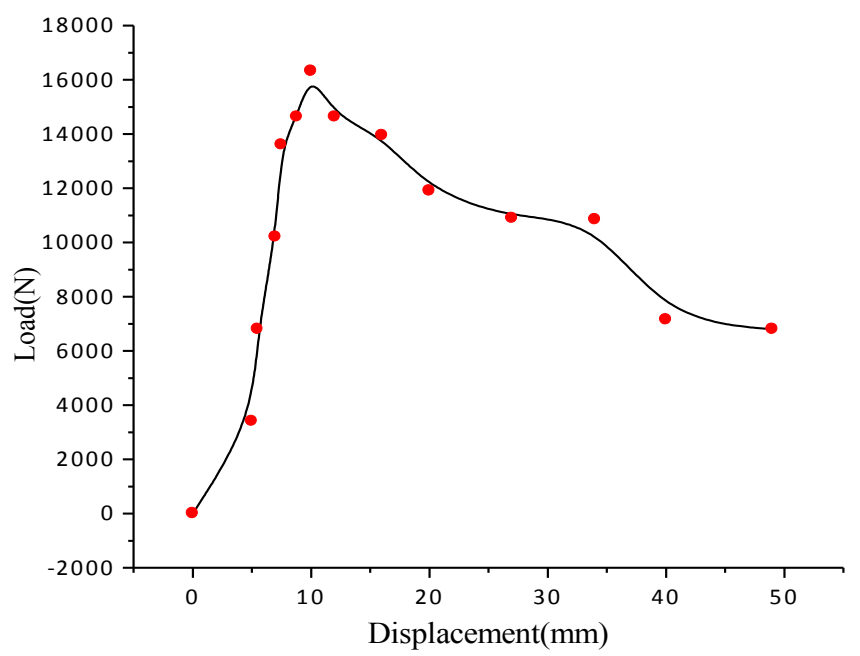

Fig. (6). Tensile test result of $\mathrm{C}$ geogrids at a steady speed.

As can be seen from the Table 4: Stretching rate decreased from $50 \mathrm{~mm} / \mathrm{min}$ to $0.05 \mathrm{~mm} / \mathrm{min}$, under the $2 \%$ strain condition, the tensile strength and tensile modulus of the type $\mathrm{C}$ of the steel-plastic geogrid decreased by $12.82 \%$. 
Table 4. Tensile test result of $\mathrm{C}$ geogrid at a different speed.

\begin{tabular}{|c|c|c|c|c|c|c|}
\hline \multirow{2}{*}{ Type } & \multirow{2}{*}{$\begin{array}{c}\text { Tensile Rate } \\
(\mathbf{m m} / \mathbf{m i n})\end{array}$} & Tensile Strength $(\mathbf{k N} / \mathbf{m})$ & Tensile Module (kN/m) & Tensile Strength (kN/m) & Tensile Modulus (kN/m) & Strain/\% \\
\cline { 3 - 7 } & & 50.78 & 2562.1 & 81.69 & 2031.2 \\
\hline \hline $\mathrm{C}$ & 10 & 49.22 & 2477.6 & 78.13 & 1965.6 \\
\hline $\mathrm{C}$ & 1 & 46.25 & 2364.0 & 76.47 & 10.42 \\
\hline $\mathrm{C}$ & 0.1 & 45.43 & 2271.4 & 75.96 & 10.87 \\
\hline $\mathrm{C}$ & 0.05 & 44.27 & 2208.2 & 68.89 & 17.0 \\
\hline
\end{tabular}

Under the 5\% strain condition, the tensile strength and tensile modulus of $\mathrm{C}$ geogrids were decreased by $15.67 \%$. In contrast, the peak strain of the geotechnical geogrid increased by $17.79 \%$.

\section{THE RESULT ANALYSIS}

(1) In the early stage of tensile steel geogrids, the adhesion of the grating and the clamp was strong, and the resistance was large, so that the tensile modulus of the whole model would increase continuously. As the tension continues to increase, the more obvious the viscous characteristics of the geogrids were, the greater the tensile modulus was. When the tension reached a certain value, the geogrid would appear with varying degrees of fracture. When the tension reaches $5.9 \mathrm{kN}$, type $\mathrm{A}$ of geogrid was broken. When the tension reached $12.29 \mathrm{kN}$, steel wires in type B of geogrid were broken, and the tensile strength was decreased rapidly. When the tension reached $17.8 \mathrm{kN}$, type $\mathrm{C}$ of geogrid occurred spinning, steel wires were separated from polyethylene coated layer, at the same time geogrid intensity gradually decreased.

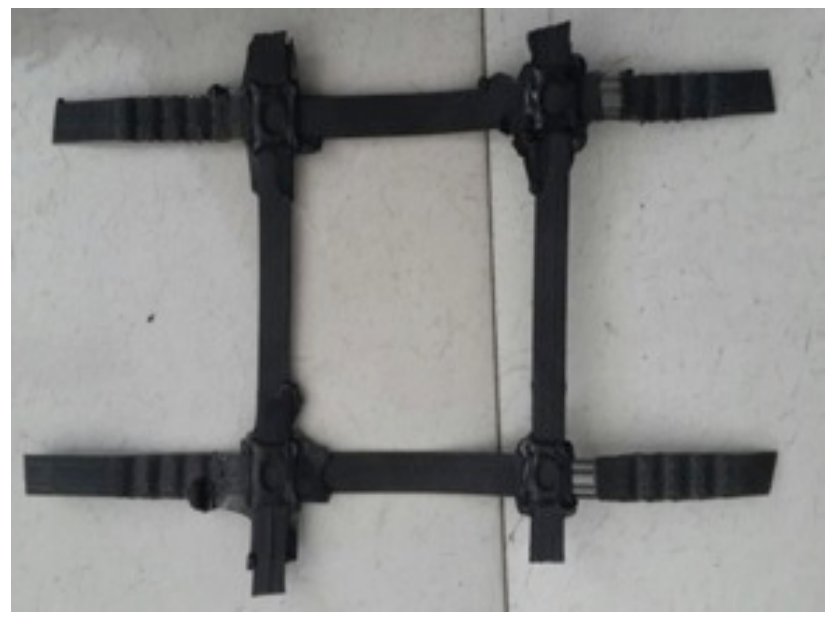

Fig. (7). $0.7 * 12$ steel-plastic geogrid.

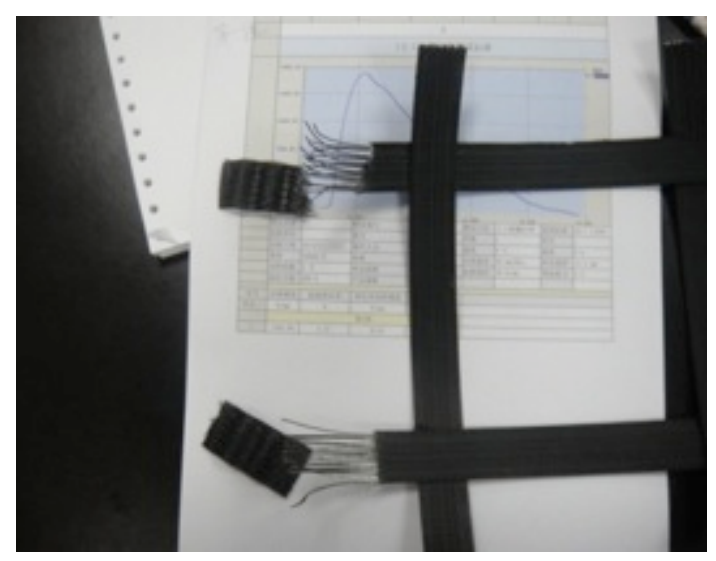

Fig. (8). 0.7*18 steel-plastic geogrid.

(2) When the stretching rate was reduced from 50 $\mathrm{mm} / \mathrm{min}$ to $0.05 \mathrm{~mm} / \mathrm{min}$, under the $2 \%$ strain condition: the tensile strength of type $A$ was decreased by $20.02 \%$; the tensile strength of type B was decreased by $18.08 \%$; and the tensile strength of type $\mathrm{C}$ was decreased by $12.82 \%$. Under the $5 \%$ strain condition, the tensile strength of type A was decreased by $19.03 \%$, the tensile strength of type B was decreased by $18.13 \%$, and the tensile strength of type $\mathrm{C}$ was decreased by $15.67 \%$. It can be seen clearly that change in type A was the biggest, and that in type $\mathrm{C}$ was the smallest. The reasons being that type A was plastic geogrid, containing no wires, and type $\mathrm{B}$ and type $\mathrm{C}$ were steel plastic geogrids, containing a certain number of wires.

When the stretching rate was reduced from 50 $\mathrm{mm} / \mathrm{min}$ to $0.05 \mathrm{~mm} / \mathrm{min}$ : the peak strain of the type A geogrid increased by $23.36 \%$; the peak strain of the type B geogrid increased by $20.52 \%$; and the peak strain of the type C geogrid increased by $17.79 \%$. The peak strain always decreased with the extension rates' increasing. The higher the material's tensile strength was, the smaller its reducing amplitude would be. At the same stretch rate, the lower the tensile strength of the geogrid was, the higher the peak strain would be. This is shown in Fig. (9).

(4) When the drawing speed is constant at $50 \mathrm{~mm} / \mathrm{min}$, geotechnical grid occurred $2 \%$ and $5 \%$ strain. The tensile strength of type A was $30.56 \mathrm{kN} / \mathrm{m}$ and 60.43 
$\mathrm{kN} / \mathrm{m}$, and the tensile modulus was $1187.6 \mathrm{kN} / \mathrm{m}$ and $983.4 \mathrm{kN} / \mathrm{m}$, respectively. The tensile strength of type B was $48.67 \mathrm{kN}$ and $93.45 \mathrm{kN}$, and the tensile modulus was $2038.5 \mathrm{kN} / \mathrm{m}$ and $1339.1 \mathrm{kN} / \mathrm{m}$, respectively. The tensile strength of type $\mathrm{C}$ was $50.78 \mathrm{kN} / \mathrm{m}$ and 93.45 $\mathrm{kN} / \mathrm{m}$, and the tensile modulus was $2562.1 \mathrm{kN} / \mathrm{m}$ and $2031.2 \mathrm{kN} / \mathrm{m}$, respectively. It is obvious that the tensile strength of the $2 \%$ and $5 \%$ strain and the peak strain of the same kind of geogrid corresponding to a certain specific tensile rate increased in turn, while the tensile modulus decreased. For the same geogrid, the greater the tensile rate was, the smaller the tensile modulus would be.

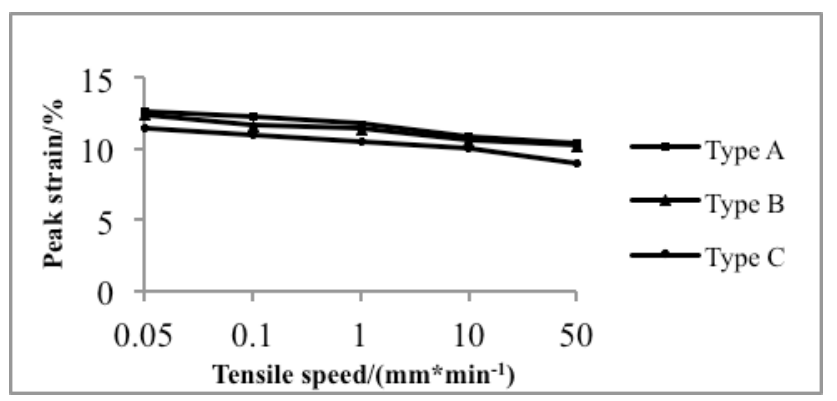

Fig. (9). The curve of peak strain and tensile speed.

\section{DISCUSSION}

The tensile test is based on some assumptions. These assumptions include that test carried out at room temperature, and geogrids were made of the same materials. However, in the actual circumstances, the working environment of the geogrids is not at room temperature, and the composition of the geogrids is not necessarily the same. So there is a certain difference between the laboratory test and the actual project based on the two assumptions. But, in practical engineering, the working environment of the geogrid is in the underground, where the change of temperature is small. Although the tensile test is simple, it is in line with the actual situation, and has more practical value.

\section{CONCLUSION}

To one kind of geogrid, its stretching rate has a significant effect on its tensile property. When the strain is constant, the higher the stretching rate is, the lower the tensile strength of the geogrid will be. When the stretching rate is constant, the greater the strain plastic geogrid is, the greater the tensile strength will be.

The peak strain always decreases with the extension rates' increasing. The higher the material's tensile strength is, the smaller the reducing amplitude will be. At the same stretch rate, the lower the tensile strength of the geogrid is, the higher the peak strain will be.

The influences on different geogrids vary when the tensile rates are different. Steel-plastic geogrid gets a lower degree of influence by the stretching rate than the plastic geogrid. When the quantity of the steel wires of the steelplastic geogrid is higher, its tensile strength gets higher, and at the same time, the stretching rate plays a decreasing part in influencing it. Both the geogrids' tensile strength and its tensile modulus are going to a lower point when the stretching rate gets down, and the same standard geogrids' tensile modulus always go up because of the increase of the stretching rate.

\section{CONFLICT OF INTEREST}

The authors confirm that this article content has no conflict of interest.

\section{ACKNOWLEDGEMENTS}

This work was financially supported by: (1) National Natural Science Foundation of China (NSFC) (41372289); (2) SDUST Research Fund (2014TDJH103); (3) A Project of Shandong Province Higher Educational Science and Technology Program (12LH03); (4) China's Post-doctoral Science Fund (2012M521365).

\section{REFERENCES}

[1] Moraci N, Gioffre D.A simple method to evaluate the pullout resistance of extruded geogrids embedded in a compacted granular soil [J]. Geotextiles and Geomembranes, 2006, 24(2): 116-128.

[2] Hou J, Zhang M X, Javadi A A, et al. Experiment and analysis of strength behaviour of soil reinforced with horizontal-vertical inclusions[J]. Geosynthetics International, 2011, 18(4): 150-158.

[3] Cai Chun, ZHANG Meng-xi, et al. Pull-out test of uniaxial geogrid with strengthening ribs[J]. Rock and Soil Mechanics, 2012. 33(1): 53-60.

[4] Shi You-zhi, MA Shi-dong. Test for interface characteristics of geogrid[J]. Rock and Soil Mechanics, 2003, 24(2): 22-24.

[5] Luan Mao-tian, XIAO Cheng-zhi, YANG Qing, et al. Experimental study on creep properties and viscoelasticity constitutive relationship for geogrids[J]. Rock and Soil Mechanics, 2005, 26(2): 187-192.

[6] Yang Ye, LIU Song-yu, et al. New measuring technology of geogrids under load[J]. Chinese Journal of Geotechnical Engineering, 2009, 31(7): 1133-1137.

[7] Wu Jing hai. Study on interaction characteristics between geosynthetics and fill materials by pull out tests[J]. Rock and Soil Mechanics, 2006, 27(4): 581-585.

[8] Gao Jie. Study on Stretch Mechanism and Process Conditions in Drawing Geogrid [J]. Journal of Beijing Institute of Petro-chemical Technology, 2002, 10(2): 28-31.

[9] Yang Guang-qing, PANG Wei, LÜ Peng. Experimental study of tensile properties of geogrids[J]. Rock and Soil Mechanics, 2008, 29(9): 2387-2391. 